\title{
A Study of the Regime Switching in the Relationship between the Tunisian Exchange Rates and the Fundamental Economic Variables: A Further Investigation Using the Threshold Cointegration Theory
}

Sami $\mathbf{R}^{*}$ and Saoussen $\mathbf{K}$

Economic Sciences and Management of Tunisia, Tunisia

\begin{abstract}
This paper introduces the regime switching models considered when determining the long run relationships between the Tunisian effective exchange rate and economic fundamentals over a period of 30 years. We employ the threshold cointegration approach in order to investigate the long run non-linear dynamics of the effective exchange rate. We introduce the threshold error correction model (TECM) to illustrate the discontinuity of the convergence process towards the long run equilibrium situation. The obtained results confirm the discontinuous or asymmetrical character of the trajectory of the Tunisian dinar towards its fundamental situation depending on whether Tunisia exchange rate is under - or overvaluation regimes. In addition, structural shifts from selected economic variables, may characterize this discontinuity in the convergence process.
\end{abstract}

Keywords: Exchange rate; Threshold cointegration; Structural breaks

\section{Introduction}

The upward complexity of many real-world problems is one of the major challenges of our time. Complexity is also one of the influencing factors in decision making in the area of international finance which has taken on great significance over the last decade [1]. Because of the structural shifts in the world economy and the international financial system, the foreign exchange market has greatly changed. Among the major developments that have occurred in the global financial environment, the following changes can be noted: A basic change in international monetary system from the fixed exchange rate requirements of the Bretton woods that existed until the early 1970 to the floating exchange rate system of today. Added to that, major advances in technology have made instantaneous real-time transmission of vast amounts of market information possible all over the world. The immediate and sophisticated manipulation of information in order to identify and exploit market opportunities, and the rapid and reliable execution of financial transactions. Furthermore, breakthroughs in the theory and practice of finance, led to the development of new financial instruments and derivate products in addition to the advancement thinking as market participants have changed their understanding of the financial system and the techniques used.

The relationship between these forces, feeding off each other in a dynamic and synergistic way, led to an environment where foreign exchange trading increased rapidly. The exchange rate is one of the most important determinants of a country's relative level of economic health. It plays a vital role in global trading and portfolio investments. In the current context of global imbalances, aggregation effect, transaction costs or uncertainty, the assessment of equilibrium values for the real exchange rate have always been important issues. For instance, many researchers have been developed to study the dynamics of exchange rate towards its behavioural equilibrium value. Hence, the purchasing power parity (PPP) approach, although relevant at a remote time horizon, does not provide any insight of exchange rate adjustments that would be consistent with world unbalances that are unravelled. Alternatively, the medium-run, fundamental equilibrium exchange rate (FEER) of may excessively focus on current account adjustment, underestimating the plasticity of the international monetary system and the existence of alternative adjustment variables. Meanwhile, the BEER "behavioural equilibrium exchange rate", consists in the estimation of a long-run or cointegrating relationship between the effective exchange rate and a set of economic fundamentals [2]. Moreover, the NATREX "natural equilibrium exchange rate" model is the most important theory that explains the dynamics of the medium-to-long run equilibrium real exchange rate. These models imply the existence of linear relationship between exchange rate and its determinants. So, several recent studies aim at looking for the reasons of the incapacity of these models in determining the factors responsible for the fluctuations of exchange rate.

In this paper, we are trying to explain the relationship between effective real exchange rate and the fundamentals variables in Tunisia. Therefore, this paper tries to show the importance of nonlinearity and structural breaks in the study of the real or monetary factors determining the effective exchange rate dynamics of the Tunisian dinar. We will show that the fundamental economic variables find their places in the determination of the convergence process of exchange rate towards its equilibrium situation. We will try empirically to determine the long run relationship between the effective exchange rate and fundamental economic variables in Tunisia using the threshold error correction model during the period of 1980-2012.

\section{Literature Reviews}

In several researches presented the obviousness of the threshold model in the real exchange rate adjustment [3-9]. The non-linear modeling enables the validation of the traditional approaches of the exchange rates such as the sticky-price monetary models of Frankel and

*Corresponding author: Sami R, Faculty, Economic Sciences and Management of Tunisia, Tunisia, Tel: +21671870277; E-mail: rez_sami2001@yahoo.fr

Received April 28, 2017; Accepted October 16, 2017; Published October 23 2017

Citation: Sami R, Saoussen K (2017) A Study of the Regime Switching in the Relationship between the Tunisian Exchange Rates and the Fundamental Economic Variables: A Further Investigation Using the Threshold Cointegration Theory. J Glob Econ 5: 266. doi: 10.4172/2375-4389.1000266

Copyright: (๑) 2017 Sami R, et al. This is an open-access article distributed under the terms of the Creative Commons Attribution License, which permits unrestricted use, distribution, and reproduction in any medium, provided the original author and source are credited. 
Rose [2] the behavioural equilibrium exchange rate models (BEER) and the fundamental equilibrium exchange rate (FEER). Standard economic models hold that exchange rates are influenced by fundamental variables such as relative money supplies, outputs, inflation rates, the terms of trade, the public deficit, interest rates. Nonetheless, many empirical researches have shown that these econometric models have performed very poorly in predicting exchange rate movements $[2,10]$. Michael et al. [8] stated that exchange rates are characterized by nonlinear adjustment toward equilibrium that can arise from transaction costs or other frictions in the international financial markets. They have well documented that fundamental variables have little help in predicting changes in floating exchange rates periods and that the speed of the mean reversion increases with the size of the deviation from equilibrium.

Several arguments of non-linearity hypothesis, i.e., the target zones theory or transaction cost propose a change of the short or long run dynamics where the exchange rate is authorized to fluctuate freely in a band fixed by the monetary authorities [11]. The central bank intervenes only when the exchange rates exceed the extreme points of the band. Therefore, the re-examinations of the error correction mechanism while using the non-linear and the non-stationary approach simultaneously describe the threshold effect on the error-correction term, which allows a discontinuous adjustment towards the cointegration relationship in the behavior of the exchange rate dynamics characterized by non-stationarity aspect. Moreover, the above reasons motivate us to explore the relationships between exchange rates and macroeconomic fundamentals by means of econometric models with structural change with unknown or known structural change point.

Indeed, with the presence of transaction cost hypothesis, show that the reaction of economic agents appears when the deviation compared to the equilibrium situation exceeds a certain critical point, giving a great advantage for the economic agents to be reacted and adjusted without interruption. This adjustment yields an economic advantage, which exceeds the transaction cost [11]. Consequently, the return to equilibrium situation in progress expresses the ideal aspect of the exchange rate dynamics. Moreover, several specifications of nonlinearities in the exchange rate modeling have been introduced while adopting the threshold cointegration approach $[4,12]$. Thus, the non-linearity in the cointegration approach has been introduced taking into account the long run nonlinear relationship between exchange rate and economic fundamentals.

The empirical approaches suggest that the relationships between the exchange rate and the fundamentals are structurally unstable [2], characterized by frequent changes in the regimes linking the exchange rate to the fundamentals. However, the econometric evolutions also aim at resolving the failure of these approaches and reinforcing the different exchange rate models by the definition of new techniques intended to visualize the real factors of exchange rate dynamics. Indeed, several authors were interested in introducing non-linearity in exchange rate models and also tried to determine a non-linear models making a possible explanation of the exchange rate dynamics in short and long run [13].

In addition, structural break has been receiving much attention in many economic fields, particularly, time series econometrics [14]. It is likely that the non-stationary in the real exchange rates could refer to the presence of structural breaks in the series have demonstrated that when a time series has structural breaks in the mean, the unit root hypothesis is often accepted before structural breaks are taken into account, while it is rejected after structural breaks are considered [15].
It was asserted that when examining the exchange rate fundamentals link, it is necessary to consider the structural change factor [16]. So, Enders and Siklos [12] examined the relationship between the longterm and short-term interest rates in an asymmetric framework.

Several important financial events such as international financial crisis makes the idea that connections between exchange rates and fundamentals have remained continuous over time considerably uncertain. Consequently, Engel and Hamilton [17] used a Markov switching model in the modeling of non-linearities and regime shifts in exchange rate trajectories. So, these authors found evidence of frequent shifts in the relation between the exchange rate and its fundamentals also applied the Markov-switching vector error correction model (VECM) to the dynamic relationships between the US dollar exchange rate and its fundamentals [18]. Their empirical findings revealed that the long-run equilibrium levels for six industrialized countries are time-varying. Thus, Bessec [6] considered a Markov- Switching Error Correction Model (MSECM) to show the existence of a discontinuous adjustment in time toward a long-run equilibrium representing the two states of the system such as the central parity during the credible periods of mean-reversion and the PPP during the speculative episodes.

Fok et al. [19] developed a multiple regime smooth transition autoregressive model to evaluate the non-linear relationship between the exchange rate and its fundamentals. Also, Taylor and Peel [10] applied the exponential smooth transition autoregression model in analyzing the non-linear cointegration relationship in the US, UK and Germany. The results indicate that during periods of small deviations from fundamentals, the exchange rate shows a unit-root. However, the authors detected a rapid adjustment of the exchange rate toward its underlying fundamentals when there are large deviations from the equilibrium. Moreover, to take into account the structural break in the economic variables dynamics, the non-linearity can intervene directly between the economic relationships, when we introduce the nonlinear Granger causality [20].

\section{Nonlinear Cointegration}

A vast empirical research has recently proposed two principal classes of the regime switching models. The first class model is the Markov regime switching model, which was initially introduced in order to specify the expansion or recession periods that characterize economic states which have an impact on the interest variable dynamics [17]. The second approach of the regime switching models presents the threshold models class where the realization of a particular regime is related to an observable variable. As an example we can mention, the case of the threshold autoregressive models (TAR) proposed by Tong and Lim (1980) and the smooth transition regression models (STAR) [20]. Indeed, the fundamental characteristic of these models, in comparison with Markov regime switching models, is that the transition from one regime to another is controlled by a transition function. It takes the form of an indicator transition function in TAR models:

$$
1_{y t-d} \leq c=\left\{\begin{array}{l}
1, \mathrm{x}_{\mathrm{t}-\mathrm{d}} \leq \mathrm{c}, \\
0, \mathrm{x}_{\mathrm{t}-\mathrm{d}} \geq \mathrm{c}
\end{array}\right.
$$

and the form of an exponential function:

$\mathrm{F}\left(\mathrm{x}_{\mathrm{t}-\mathrm{d}} \gamma, \mathrm{c}\right)=1-\exp \left[-\gamma\left(\mathrm{x}_{\mathrm{t}-\mathrm{d}}-\mathrm{c}\right)^{2}\right]$ in the case of ESTAR model or logistic transition function in the case of the LSTAR models: $G(x$ $\left.{ }_{d}, \gamma, c\right)=\left[1+\exp \left[\left(-\gamma\left(x_{t-d}-c\right)\right)\right]^{-1}\right.$, where, $x_{t}-d$ : the threshold variable and $c$ : The threshold parameter.

In particular studies, Balke and Fomby [4], Hansen [21], Hansen 
and Seo [22], have been interested in the contribution of the threshold cointegration theory in the study of the economic variables dynamics within a univariate or multivariate framework. These authors have obviously proposed the assumption that the adjustment towards the long run equilibrium is not necessarily realized during each time. This leads to the reexamination of the system stipulating a continuous correction mechanism for the equilibrium residual. This can for example occur with the presence of the fixed costs that prevent the economic agents to be adjusted in a continuous way independently of their external environment, which necessarily causes constraints. This fixed cost conditions the reaction of the economic agents to the deviation by the equilibrium situation.

Therefore, the econometric procedure adopted by Balke and Fomby [4], Enders and Siklos [12] which authorizes a discontinuous adjustment towards the long run equilibrium, is proposed. A methodology based on the adjustment of the equilibrium deviation that is schematized by a threshold auto regression model (TAR) has been followed. This methodology presents a conditional aspect, which authorizes the amplitude correction compared to the equilibrium situation when this equilibrium error exceeds a certain threshold parameter. Moreover, the Gregory and Hansen [23] approach which proposes three dissimilar formulations for the switching mechanism in the long run relationship has been adopted. Thus, these authors propose the structural breaks to be carried out simultaneously on the constant of the model or at the level of the constant and the vector of cointegration, in order to schematize the long run exchange rate discontinuous dynamics. What is more, the use of threshold cointegration theory is paramount in the hypothesis of the non-linear cointegration relationship between exchange rate and its fundamentals. Thus, this theory is proposed to capture the non-linear adjustment process, to manage and to organize different configurations characterizing the long run exchange rate dynamics.

In fact, Balke and Fomby [4] introduced the threshold cointegration within a univariate framework while supposing the uniqueness and the knowledge of cointegration vector. However, proposed a more general approach than that of Balke and Fomby [4] in which they introduced the threshold cointegration theory within a multivariate framework with the hypothesis of a known cointegration vector. Another specification of the threshold cointegration theory, which presents its characteristic compared to the other approaches, is that it adopts the formulation suggested initially by Hansen and Seo [22] and reexposed by Aslanidis and Kouretas [24], these authors, indeed, exposed the threshold cointegration within a multivariate framework. Obviously, Hansen and Seo [22] examined the two regimes threshold cointegration theory through considering a threshold vector errors correction model (TVECM).

Balke and Fomby [4] exposed the threshold cointegration concept in two different ways. The first approach consists of the threshold cointegration theory through the discontinuity of the evolution process of the long run relationship residual. The second approach, conceptualizes the phenomenon of threshold cointegration through the threshold error correction models (Threshold ECM). The formulation of the first approach evoked by Balke and Fomby [4] focused on the discontinuous evolution process of the long run equation of residual and was introduced through an econometric representation, an approach taken by Engle and Granger (1987). Two variable $X_{t}$ and $Y_{t}$ which appear in the following equation, have been considered:

$\mathrm{y}_{\mathrm{t}}+\alpha \mathrm{x}_{\mathrm{t}}=\mathrm{z}_{\mathrm{t}}, \mathrm{z}_{\mathrm{t}}=\rho^{\mathrm{i}} \mathrm{z}_{\mathrm{t}-1}+\varepsilon_{\mathrm{t}}$

$$
\mathrm{y}_{\mathrm{t}}+\beta \mathrm{x}_{\mathrm{t}}=\mathrm{B}_{\mathrm{t}}, \mathrm{B}_{\mathrm{t}}=\mathrm{B}_{\mathrm{t}-1}+\eta_{\mathrm{t}}
$$

where, $\varepsilon_{t}$ and $\eta_{t}$ are identically and independently distributed and mean zero random variables. In fact, equation 1 presents an equilibrium relationship between $y_{t}$ and $x_{t}$ defining, therefore, the target situation where $z_{t}$ is the deviation compared to this equilibrium situation. We also announce that $(1, \alpha)$ is the cointegration vector. Moreover, equation 2 introduces the notion of common stochastic tendency between variables yt and $\mathrm{xt}$ in the study of the cointegration theory. In fact, it is about an approach which reformulates the approach it reexamines the constancy of error correction mechanism and its independence with the economic reality. This reexamination takes into account, for example, the assumptions of the transaction costs or the target zones theory, in the modeling of the exchange rate dynamics. This can represent an evidence of the threshold mechanism which becomes candidate to treat problems of the exchange rate dynamics.

\section{Threshold Error Correction Models: TECM}

An approach of representing the threshold cointegration uses the threshold error correction model (TECM) as a tool to specify this nonlinear or threshold evolution of interest variables. Balke and Fomby [4], Enders and Siklos [12] rewrote the system given by Engel and Hamilton [17] approach that the adjustment towards equilibrium depends on the various scenarios evoked by the long run residuals relationship between the variables. Thus, the way of the threshold cointegration theory is postulated through the threshold error correction mechanism models within a univariate framework such as Enders and Siklos [12]. It is noteworthy to point out that the long run equilibrium relationship is as follows:

$\mathrm{y}_{\mathrm{t}}+\mathrm{ax}_{\mathrm{t}}=\mathrm{z}_{\mathrm{t}}$ and the error correction model (ECM) can be defined as follows :

$$
\left\{\begin{array}{l}
\Delta \mathrm{y}=\gamma_{1}^{\mathrm{i}} \mathrm{z}_{\mathrm{t}-1}+\delta_{1 \mathrm{t}} \\
\Delta \mathrm{x}=\gamma_{2}^{\mathrm{i}} \mathrm{z}_{\mathrm{t}-1}+\delta_{2 \mathrm{t}}
\end{array}\right.
$$

where,

$$
\begin{aligned}
& \mathrm{z}_{\mathrm{t}-1}=\mathrm{y}_{\mathrm{t}-1}+\alpha \mathrm{x}_{\mathrm{t}-1}, \gamma_{1}^{\mathrm{i}}=\frac{-\left(1-\rho^{\mathrm{i}}\right) \beta}{\beta-\alpha}, \gamma_{2}^{\mathrm{i}}=\frac{\left(1-\rho^{\mathrm{i}}\right)}{\beta-\alpha} \\
& \begin{cases}\tilde{\mathrm{n}}^{\mathrm{i}}=1, & \left|\mathrm{z}_{\mathrm{t}-1}\right| \leq \mathrm{c} \\
\tilde{\mathrm{n}}^{\mathrm{i}}=\tilde{\mathrm{n}}, & \left|\mathrm{z}_{\mathrm{t}-1}\right|>\mathrm{c} \text { avec }|\rho|<1\end{cases}
\end{aligned}
$$

On the one hand, the error correction term $\mathbf{z}_{\mathbf{t}-1}$ represents the error of equilibrium or the deviation from equilibrium in the preceding situation. On the other hand, parameters $\tilde{a}_{2}^{i}$ and $\tilde{a}_{1}^{i}$ provide the way according to which $Y_{t}$ and $X_{t}$ necessarily respond to deviations compared to equilibrium. When these parameters are equal to zero, variables $\mathrm{Y}_{t}$ and $\mathrm{X}_{t}$ do not respond to the deviations compared to the equilibrium situation. Thus, the only condition, as illustrated by Balke and Fomby [4] is that where interest variables respond to the deviations in particular situations. The convergence process towards equilibrium is carried out when the deviations exceed the threshold parameter and the coefficients $\tilde{\mathrm{a}}_{2}^{\mathrm{i}}$ and $\tilde{\mathrm{a}}_{1}^{\mathrm{i}}$ which are not null.

\section{Threshold deviation from long run equilibrium}

The discontinuity of the convergence process towards the equilibrium situation appears by the discontinuous correction of the deviation $\left(\mathrm{z}_{\mathrm{t}}\right)$ from equilibrium relationship to each regime. Thus, Balke and Fomby [4], Enders and Siklos [12], consider the variation, compared to the equilibrium situation or the error correction term $\left(z_{t}\right)$ 
as the transition variable which controls the transition from one regime to another. It is presented in the following equation :

$$
z_{t}=\rho^{i} z_{t-1}+\varepsilon t \quad \text { and }\left\{\begin{array}{ll}
\rho^{i}=1, & \left|z_{t-1}\right| \leq c \\
\rho^{i}=\rho, & \left|z_{t-1}\right|>c
\end{array} \quad \text { with }|\rho|<1\right.
$$

Explicitly, the threshold formulation of variable $\left(\mathrm{z}_{\mathrm{t}}\right)$ is schematized in discontinuity in the correction process of the deviation from the equilibrium situation. It conditions the convergence process of the variables towards the equilibrium situation. In order to illustrate the discontinuity of the convergence process towards the long run equilibrium situation, the threshold dynamics of the deviation from equilibrium is presented explicitly:

$$
z_{t}=\left\{\begin{array}{l}
z_{t-1}+\varepsilon_{t},\left|z_{t-1}\right| \leq c \\
\rho z_{t-1}+\varepsilon_{t},\left|z_{t-1}\right|>c
\end{array} \quad \text { with }|\rho|<1\right.
$$

with, (C) representing the threshold parameters which identify the situations according to the evolution processes $Z_{t}$ that guarantee the convergence process of variables $Y_{t}$ and $X_{t}$ towards the equilibrium situation. In contrast to unit root tests, such as ADF, PP and KPSS discussed in linear models, cointegration-based tests focus on the nonlinear properties of the residual term $\mathrm{Z}_{\mathrm{t}}$.

The description of this econometric representation conditions a threshold modelling of the long run equation residual and takes a particular way to model the variability of these residuals. Thus, if coefficient $\rho^{i}$ takes value 1 , variable $Z_{t}$ is schematized by a random walk process $\left(\mathrm{z}_{\mathrm{t}}=\mathrm{z}_{\mathrm{t}-1}+\varepsilon_{\mathrm{t}}\right)$ which, by definition, is a nonstationary process. Indeed, in this case $\mathrm{Z}_{\mathrm{t}}$ becomes similar to a unit root process and consequently the adjustment mechanism of variables $Y_{t}$ and $X_{t}$ does not have any tendency to turn over towards the long run target or the equilibrium situation. In addition, if $Y_{t}$ and $X_{t}$ with $|\rho|<1$, the process is stationary and the adjustment mechanism of interest variables has a tendency to turn over towards the equilibrium situation and therefore the process of convergence towards equilibrium is carried out.

\section{Econometric Procedure and Results}

This study relates to the Tunisian dinar exchange rate according to the currencies of Tunisian main partners, in order to determine whether the effective real exchange rates evolved is compatible with the Tunisia's fundamental economic situation. The following procedure is followed. In order to learn the nature of the relationship between the exchange rates and the fundamental economic variables, the long run relationship, basing on the modelling of the BEER approach which was proposed initially by Hansen [25] and retained by Levin et al. [26] has been studied:

$$
\text { rer }_{t}=\alpha_{0}+\alpha_{1} \text { tot }_{t}+\alpha_{2} \text { open }_{t}+\alpha_{3} \text { nfa }_{t}+\alpha_{4} \text { gov }_{t}+\alpha_{5} \text { balass }_{t}+\alpha_{6} \operatorname{dint}_{t} t_{t}
$$

\section{Construction of the variables}

The construction of the fundamental variables are initially presented, taking into account in the selected model, the following countries representing the trade partners of Tunisia (France, Germany, Italy, Belgium, the Netherlands, Spain and USA). The data are obtained from two sources: the IMF's International Financial Statistics and the world development indicator (WDI) and these are annual data over 32 years, from 1980 to 2012 .

Rer : The real effective exchange rate (REER) is calculated as the relationship between the real effective domestic exchange rate and the real effective exchange rate of the partners. The calculation is balanced by respective weight $\mathrm{W}_{\mathrm{i}, \mathrm{j}}$ of each partner belonging to the selected sample. The variable is log transformed: Logrer as shown in Figure 1.

$$
\operatorname{RER}_{\mathrm{i}}=\frac{\mathrm{REER}_{\mathrm{i}}}{\sum_{\mathrm{j}=1} \mathrm{w}_{\mathrm{i}} \text { REER }_{\mathrm{J}}}
$$

Tot : The terms of trade of Tunisia, this variable is defined as the relationship between the value of domestic exports and imports relative to the relationship between value of exports

(X) and imports (M) of other partners. The variable is log transformed: logtot as shown in Figure 2

$$
\operatorname{TOT}_{\mathrm{i}}=\frac{\frac{\mathrm{Xi}}{\mathrm{Mi}}}{\sum_{\mathrm{j}=1} \mathrm{w}_{\mathrm{irj}} \frac{\mathrm{Xi}}{\mathrm{Mj}}}
$$

$\left(r_{t}-r_{t}^{*}\right)$ : Differential of interest rate enters the domestic interest rate (nominal interest rate of the Treasury bills at 10 years) $r_{t}$ and the interest rate ${ }^{r_{t}}$ calculated like a weighted average of the interest rates of the trade partners as shown in Figure 3.

Gov: The ratio of the public deficit (dett) to the domestic GDP relative to the ratio of the public deficit to the GDP of the trade partners: which is shown in Figure 4.

$$
\operatorname{Gov}_{i}=\frac{\frac{\operatorname{Gov}_{i}}{\operatorname{PIB}_{i}}}{\sum_{j=1}^{k} w_{j} \frac{\operatorname{Gov}_{j}}{\operatorname{PIB}_{j}}}
$$

Nfa : The value of net foreign assets of GDP which is defined as the relationship between the net foreign assets and the domestic GDP, relative to the relationship between the net foreign assets and the GDP of the trade partners as shown in Figure 5.

Open: The degree of the economy opening

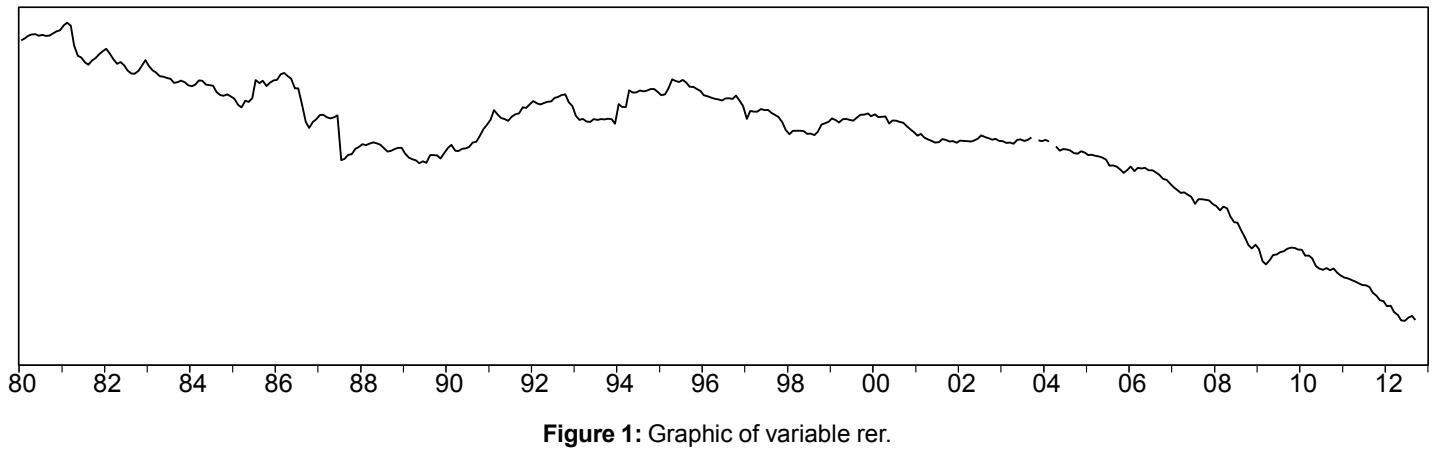



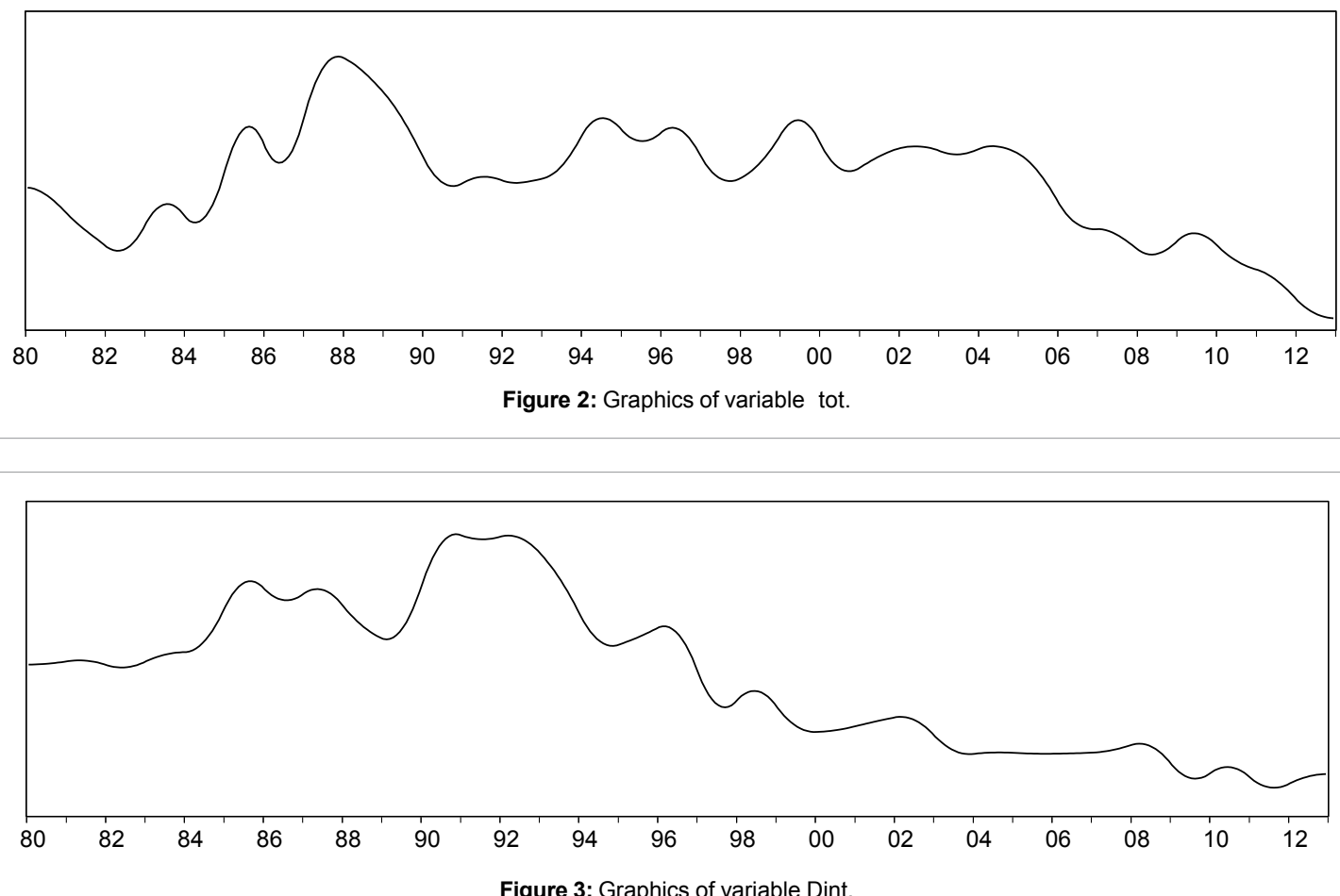

Figure 3: Graphics of variable Dint.
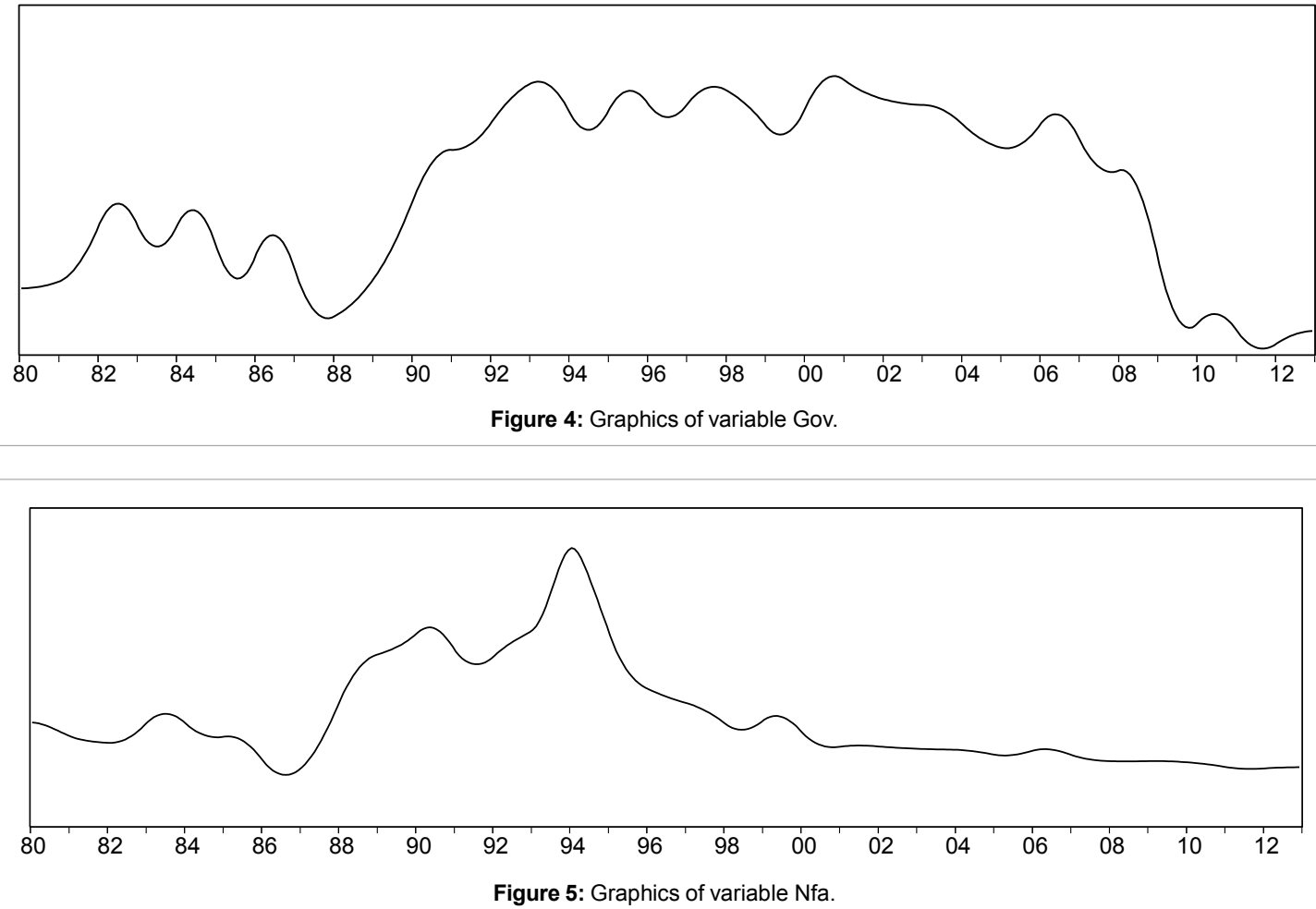

$$
\operatorname{OPEN}_{i}=\frac{\frac{X_{i}+M_{i}}{G D P_{i}}}{\sum_{j=1} w_{j} \frac{X+M}{G D P}}
$$

with, $\mathrm{X}_{\mathrm{i}}$ and $\mathrm{M}_{\mathrm{i}}$ represent respectively the value of the exports and imports of the country in question. The variable is log transformed: logopen as shown in Figure 6.

Balass: In Figure 7 measures the effect Balassa Samuelson. This 


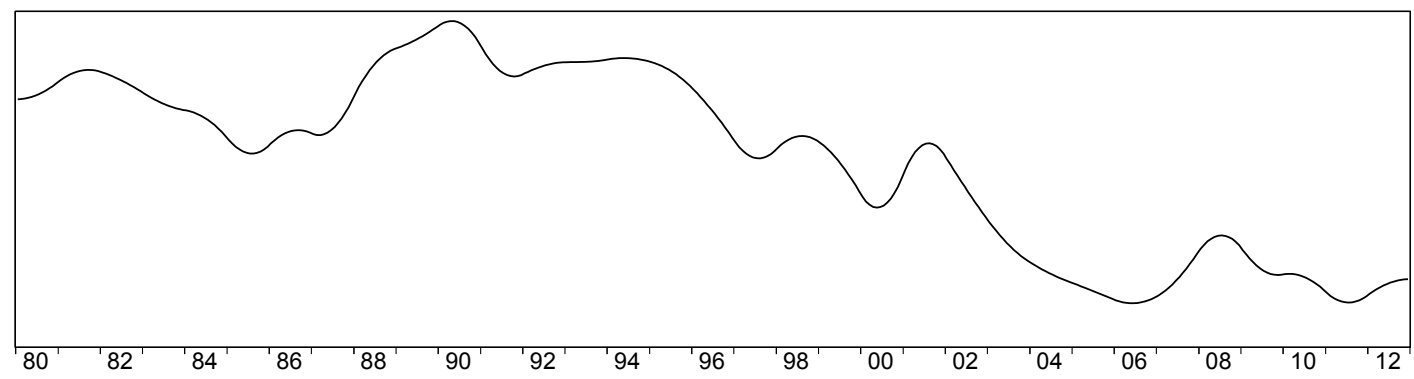

Figure 6: Graphics of variable open.

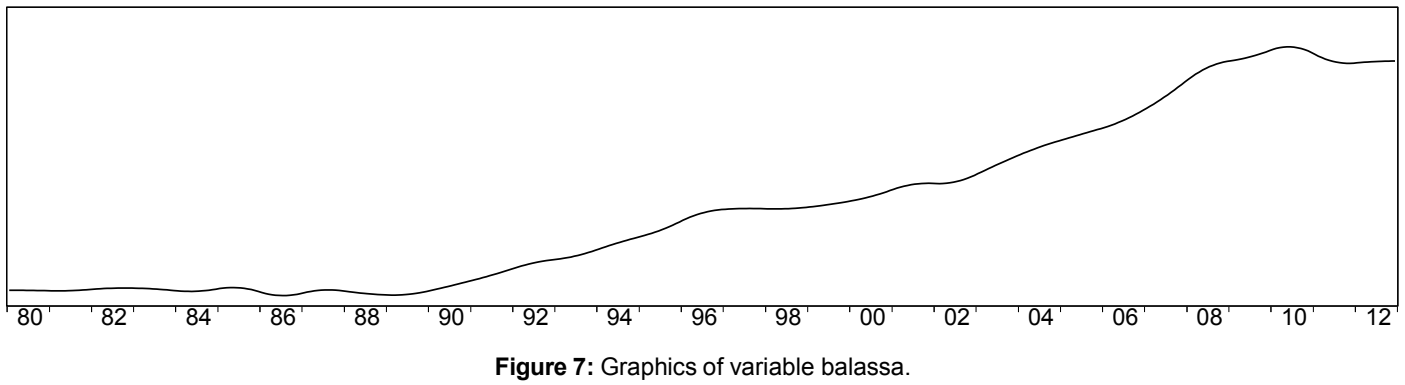

variable measures the effect of the increased productivity of the exchangeable products on the misalignment of the exchange rate. The variable Balasst is given as a relationship between the GDP PPP per capita of the considered country and the weighted average of the GDP PPP per capita of the countries which are partners of Tunisia.

\section{Unit root tests}

In general, the following step is taken in this study. In fact, the study represents a proof of the importance of non-linearity hypothesis in the empirical studies of the economic variables dynamics as shown in Table 1 .

The results of the unit root tests and stationnarity analysis of the interest's variables determine particularly the choice of the empirical methodology which can be a possible solution to the problem of determining the equilibrium exchange rate and its misalignment. The results of stationarity tests are presented in Table 1.1 and Table 2.

The null hypothesis of a unit root is rejected. The result is confirmed by the superiority of the test statistics compared to critical value for ADF and PP tests. The results of Tables 1 and 2 of unit root test show that the fundamental variables are nonstationary at level but stationary in the first difference. The considered cointegration theory represents, therefore, the fundamental technique in favor of the non stationnarity of the interest's variables.

So, the validity of the cointegration relationship between the effective real exchange rate and the fundamental economics such as the degree of the economy opening (open), The value of net foreign assets (nfa), the Balassa Samuelson effect (balass), the real interest rate (INT) and the public expenditure or the foreign debt (Gov) must be necessarily related to the recent advancements in the cointegration approaches.

\section{Testing the linear cointegration}

The analysis of the unit root and stationnarity tests of the variables

\begin{tabular}{|c|c|c|}
\hline & Threshold Behavior & Linearity \\
\hline Stationary hypothesis & Threshold, no cointegration & Linearity, no cointegration \\
\hline Nonstationary hypothesi & Threshold Cointegration & Linear cointégration \\
\hline \multicolumn{3}{|c|}{ Table 1: Threshold behaviour. } \\
\hline Variables in level & ADF test & PP test \\
\hline RER & $-2.868988(0.7243)$ & $-2.868771(1.0472)$ \\
\hline OPEN & $-2.868908(-0.5584)$ & $-2.868638(-0.6280)$ \\
\hline TOT & $-3.421362(-1.4776)$ & $-3.421241(-1.3898)$ \\
\hline NFA & $-1.941662(-1.1431)$ & $-1.941628(-1.2247)$ \\
\hline GOV & $-3.421358(-0.3821)$ & $-3.421241(-0.4692)$ \\
\hline BALASS & $-3.421358(-2.2580)$ & $-3.421241(-2.4629)$ \\
\hline DIFINT & $-1.941636(-0.9419)$ & $-2.868638(-0.2964)$ \\
\hline
\end{tabular}

Table 1.1: Results of unit root test of variables in level. (critical value $5 \%$ ).

\begin{tabular}{|l|l|l|}
\hline Variables in first difference & ADF Test & \multicolumn{1}{c|}{ PP Test } \\
\hline RER & $-2.869029(-8.3021)$ & $-2.868829(-16.6551)$ \\
\hline OPEN & $-1.941638(-6.2791)$ & $-1.941630(-3.8847)$ \\
\hline TOT & $-2.868732(-7.1880)$ & $-1.941630(-4.2456)$ \\
\hline NFA & $-2.868732(-5.3995)$ & $-1.941630(-3.9121)$ \\
\hline GOV & $-3.421388(-7.5641)$ & $-2.868657(-4.1976)$ \\
\hline BALASS & $-2.868732(-4.0834)$ & $-1.941630(-2.2742)$ \\
\hline DIFINT & $-1.941638(-6.5611)$ & $-1.941630(-3.9877)$ \\
\hline
\end{tabular}

Table 2: Results of unit root test of variables in the first difference.

prove that all these variables are integrated of order 1 . Thus, the cointegration theory will be used to capture any possible existence of a long run relationship between the real exchange rate and the selected economic fundamentals despite their nonstationary aspects. In fact, the stationnarity of the long run relationship residing between these variables, proves that the real exchange rate (Rer), the terms of trades (tot), the degree of the economy opening (open), the value of net foreign assets (nfa), the Balassa Samuelson effect (balass), the differential of the 
real interest rate (dint) and the public expenditure or the foreign debt (Dett), can, nevertheless, form a long run relationships.

The unit root tests (ADF, PP and DF-GLS) give similar results and prove, particularly, the non stationary character of the residue of the cointegration relationship. Therefore, the results of tests (Table 3) prove systematically the acceptation of the non cointegration assumption between the Tunisian real exchange rate and the economic fundamentals selected. This paper presents an even thorough study through a focus on the graph of residue of the cointegration relationship.

The trajectory of the residue can, graphically, be broken up at least in two different parts; it seems natural to allow for the existence of different states of the world or regimes as shown in Figure 8.

There are two different parts presented in the amplitude of this residue that can induce directly the cointegration relationship vector to be variable in time leading to going back to the linearity assumption of the long term relationship. There must be therefore a fundamental reason to reject the null assumption of the linear cointegration. In fact, presenting this preliminary decomposition casts doubt on a certain discontinuity in the trajectory of the cointegration relationship residue between the effective Tunisian exchange rate and the economic fundamentals. So, the rejection of the linear cointegration between the variables, can probably be caused by the presence of structural changes at the unknown time in the variables trajectories allowing the dynamics to be different in various regimes.

\section{Analyze stationarity with structural breaks}

The rejection of linear cointegration between the variables of interest may probably have several reasons: presenting two different parts in terms of the residual amplitude of the long- term relationship could directly induce that the vector of cointegration is variable in time. This result gives place to a non-linear decomposition of the trajectory of the residue. Therefore, a nonlinear model is to be used to describe this trajectory properly. In addition, the possible existence of unknown structural breaks may give erroneous results concerning the classical root tests (ADF,PP,KPSS) and probably explains the rejection of the null hypothesis of linear cointegration. Hence, tests for parameter instability and structural change in regression models have been an important part of applied econometric work.

Several empirical and theoretical researches have addressed the

\begin{tabular}{|l|l|l|l|}
\hline Variable & ADF Test & PP test & DF-GLS test \\
\hline$Z_{\mathrm{t}}$ & -3.219 & -2.7242 & -0.6905 \\
\hline & $(-3,446)^{\mathrm{a}}$ & $(-2,868)^{\mathrm{b}}$ & $(-1,941)^{\mathrm{c}}$ \\
\hline
\end{tabular}

Table 3: Results of unit root test of the residue of the cointegration relationship. (a $=1 \%, \mathbf{b}$ and $\mathbf{c}=5 \%)$. $\mathrm{Z}_{\mathrm{t}}$ : The residue of the cointegration relationship. problem of structural breaks when testing for unit root processes. Terasvitra and Anderson [27], Hansen [28] proposed determining the break point endogenously from the data. Hall et al. [29] extended the model to accommodate two structural breaks.

The results of these tests (Tables 4 and 5) confirm the nonstationarity of the selected fundamental economic variables since the test values for all variables are higher than the critical values at the threshold of $1 \%(-4.93)$ and 5\% (-4.42). The residual of the long-term relationship is non-stationary using the three models cited in Table 5, integrating two unknown ruptures and this is confirmed by the fact that the test statistics are all higher than the values (1\%,5\% and $10 \%)$.

In this regard, methodology evoked by Balke and Fomby [4], Enders and Siklos [12] Gregory and Hansen [23] have been followed in this study to discuss the points to be deal with. So, the main objective is to find a mechanism translating discontinuity in the cointegration relationship between the Tunisian real effective exchange rate and the fundamental economic variables. To take this issue into account, tests have been introduced for cointegration with one unknown structural break and tests for threshold effect cointegration ware also available.

\section{Test of threshold effect or nonlinearity}

The Teräsvirta [20] approach has been adopted to evaluate the nonlinear property of the residual term of the threshold cointegration relationship between the Tunisian exchange rate and the fundamental variables. This estimation procedure shows that the optimum selection of the delay parameter is $\mathrm{p}=4$. Teräsvirta [20] has a specification procedure starting with the null hypothesis of linearity opposed to the alternative hypothesis of threshold or nonlinear approach. The rejection of the null hypothesis of non-linear cointegration, indicates the presence of the threshold cointegration between each variable. Thus, once the alternative hypothesis is accepted, Teräsvirta [20] presents a sequence of hypothesis testing ( $\mathrm{H} 01, \mathrm{H} 02$ and $\mathrm{H} 03)$ to choose between ESTAR and LSTAR processes. The following table shows the results of the linearity test versus the alternative threshold as shown in the Table 6 .

In this context, the linearity versus the alternative threshold approach is strongly rejected for the four possible values of the delay parameter. In addition, the probabilities associated with other tests seem to be very low, especially for the delay parameter $\mathrm{d}=1$; which makes a nonlinear modelling type STAR possible. In other words, we cannot exclude the possibility of ESTAR, LSTAR, or the type of linearity in the following non-linear modelling of long-term relationship between the exchange rate and its fundamentals cannot be excluded. It can also be noted that the Fisher statistic is significant for $\mathrm{H} 01$ and all possible values of $d$. However, the Fisher statistic is not significant for $d=2$ for $\mathrm{H} 01$ and $\mathrm{H} 03$ for $\mathrm{d}=\{3,4\}$.

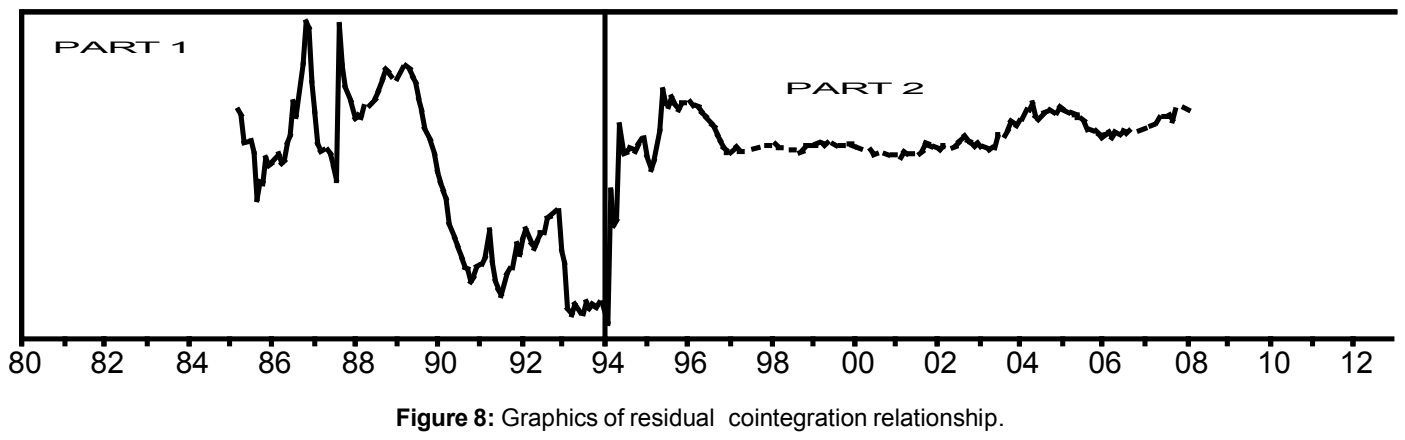




\section{Threshold Error Correction Model of Tunisian Exchange Rate}

\section{Threshold ECM Model presentation}

This part starts with a presentation of the linear error correction model based on the hypothesis that there is a linear and continuous correction system. The short term fluctuations within this framework is unaware of the possibility of the existence of the nonlinearity or switching regime assumption between the effective real exchange rate and the fundamental economic variables [30].

$$
\Delta \mathrm{rer}_{\mathrm{t}}=\mathrm{c}+\beta_{0} \widehat{\mathrm{z}}_{\mathrm{t}-1}+\sum_{\mathrm{i}} \mathrm{a}_{\mathrm{i}} \Delta \mathrm{X}_{\mathrm{t}-1}+\sum_{\mathrm{i}} \mathrm{b}_{\mathrm{j}} \Delta \mathrm{rer}_{\mathrm{t}-\mathrm{j}}+\varepsilon_{\mathrm{t}},
$$

with, $\mathrm{Xt}=$ (open, $\mathrm{nfa}$, tot, dett, balass, dint, $), \Delta \mathrm{Xt}=\Delta_{\text {open, }}, \Delta_{\text {nfa, }}, \Delta_{\text {dett, }}, \Delta_{\text {balass, }}$ $\Delta_{\text {dint }}$

\section{$\Delta \mathrm{Xt}=\mathrm{Xt}-\mathrm{Xt}(-1)$}

By giving a detailed attention to the assumption of nonlinearity within the framework of the cointegration theory, it has been noticed that this method has been found to be effective in modeling nonlinear behavior in economic and financial variables, authorizing nonlinear

\begin{tabular}{|c|c|c|}
\hline Variables & Zivot- Andrew test & Breaks \\
\hline Rer & $-2.6026(-4.93)^{\star}$ & $1990 \mathrm{M} 08$ \\
\hline Open & $-4.5905(-5.08)^{\star}$ & $1987 \mathrm{M02}$ \\
\hline NFA & $-2.9799(-4.42)^{\star}$ & $1989 \mathrm{M} 03$ \\
\hline TOT & $-3.5865(-5.08)^{\star}$ & $1986 \mathrm{M} 02$ \\
\hline DI & $-3.4373(-4.93)^{\star}$ & $1996 \mathrm{M} 02$ \\
\hline GOV & $-3.05377(-5.08)^{\star}$ & $1988 \mathrm{M} 12$ \\
\hline BALASS & $-2.769(-4.42)^{\star}$ & $1985 \mathrm{M} 04$ \\
\hline Residue & $-4.7467(-5.08)^{\star}$ & $1990 \mathrm{M} 06$ \\
\hline
\end{tabular}

${ }^{*}$ Critical values: $5 \%$.

Table 4: Results of the zivot-andrew unit root test with structural rupture. adjustments towards the long run target and recommending, therefore, diversified states of error correction mechanisms. Indeed, the study of the cointegration theory with threshold effect is based primarily on the choice of the suitable methodology responding to the topic of this study. In fact, the uniqueness of the cointegration relationship vector and its identification can direct the nonlinear strategy of cointegration, by the supposition of a nonlinear strategy of univariate cointegration relationship such as the Balke and Fomby [4] approaches which typically adapt to the research question.

Several researches considered some factors, such as the asymmetry of the business cycle and the existence of transaction costs on the financial markets, in order to justify the resort to the nonlinearity assumption within the framework of the cointegration theory. The following methodology is presented, then the univariate threshold cointegration is treated as follows :

$$
\Delta \operatorname{rer}_{\mathrm{t}}=\left\{\begin{array}{c}
\beta_{0}+\beta \hat{\mathrm{z}}_{\mathrm{t}-1}+\sum_{\mathrm{i}} \mathrm{a}_{\mathrm{i}} \Delta \mathrm{X}_{\mathrm{t}-\mathrm{i}}+\sum_{\mathrm{j}} \mathrm{b}_{\mathrm{j}} \Delta \mathrm{rer}_{\mathrm{t}-\mathrm{j}}+\varepsilon_{\mathrm{t}}, \mathrm{z}_{\mathrm{t}-\mathrm{d}} \leq \mathrm{c} \\
\gamma_{0}+\gamma \hat{\mathrm{z}}_{\mathrm{t}-1}+\sum_{\mathrm{i}} \alpha_{\mathrm{i}} \Delta \mathrm{X}_{\mathrm{t}-\mathrm{i}}+\sum_{\mathrm{j}} \delta_{\mathrm{j}} \Delta \mathrm{rer}_{\mathrm{t}-\mathrm{j}}+\varepsilon_{\mathrm{t}}, \mathrm{z}_{\mathrm{t}-\mathrm{d}}>\mathrm{c}
\end{array}\right.
$$

with, $\mathrm{c}$ : the threshold parameter, $\mathrm{Z}_{\mathrm{t}-\mathrm{d}}$ : the residue of the cointegration relationship representing the transition variable from one state to another in this empirical methodology and $\mathrm{d}$ : the delayed parameter.

Thus, the analysis of the threshold cointegration theory is based on the evolution of the trajectory of the residue of the cointegration relationship. The choice of the transition variable $\left(\mathrm{Z}_{\mathrm{t}-\mathrm{d}}\right)$ or the delay parameter $(\mathrm{d})$ and the transition function represents a fundamental stage in the execution of this methodology. The specification procedure of Tsay [30] is based primarily on the recursive estimate mechanism of the ordered observations for each possible transition variable. For a given order $\mathrm{p}$ of the autoregressive model, Tsay [30] proves that the optimal delay parameter $\mathrm{d}$ can be obtained by the calculation of the following Fisher statistic, for an ordered regression of each possible

\begin{tabular}{|c|c|c|c|c|c|c|c|c|}
\hline \multirow{2}{*}{$\begin{array}{l}\text { Variable } \mathrm{Z}_{\mathrm{t}} \\
\text { Model } 1\end{array}$} & \multicolumn{8}{|c|}{ Unit Root Test With Two Breaks: Lumsdaine Et Papell Test } \\
\hline & \multicolumn{8}{|c|}{$\Delta \mathrm{z}_{\mathrm{t}}=\alpha+\beta_{1} \mathrm{DU}_{1 \mathrm{t}}+\beta_{2} \mathrm{DU}_{2 \mathrm{t}}+\gamma \mathrm{t}+\rho \mathrm{z}_{\mathrm{t}-1}+\sum_{i=1}^{n} \varphi \Delta \mathrm{z}_{\mathrm{t}-1}+\varepsilon_{\mathrm{t}}$} \\
\hline \multirow[t]{2}{*}{ Breaks } & 1990:06 & 0.097 & 0.0458 & 0.0406 & -0.0003 & 0.0002 & 0.0003 & -0.2766 \\
\hline & 1998:09 & (4.277) & (2.4414) & (2.3396) & (4.2772) & $(0.6326)$ & (1.3133) & $(-5.2756)$ \\
\hline Model 2 & \multicolumn{8}{|c|}{$\Delta \mathrm{z}_{\mathrm{t}}=\alpha+\theta_{1} \mathrm{DT}_{1 \mathrm{t}}+\theta_{2} \mathrm{DT}_{2 \mathrm{t}}+\gamma \mathrm{t}+\rho \mathrm{z}_{\mathrm{t}-1}+\sum_{i=1}^{k} \varphi \Delta \mathrm{z}_{\mathrm{t}-1}+\varepsilon_{\mathrm{t}}$} \\
\hline \multirow[t]{2}{*}{ Breaks } & 1990:06 & 0.097 & 0.0458 & 0.0406 & -0.0003 & 0.0002 & 0.0003 & -0.2766 \\
\hline & 1998:09 & $(4.277)$ & (2.4414) & $(2.3396)$ & $(4.2772)$ & $(0.6326)$ & $(1.3133)$ & $(-5.2756)$ \\
\hline Model 3 & \multicolumn{8}{|c|}{$\Delta \mathrm{z}_{\mathrm{t}}=\alpha+\beta_{1} \mathrm{DU}_{1 \mathrm{t}}+\beta_{2} \mathrm{DU}_{2 \mathrm{t}}+\gamma \mathrm{t}+\theta_{1} \mathrm{DT}_{1 \mathrm{t}}+\theta_{2} \mathrm{DT}_{2 \mathrm{t}}+\rho \mathrm{z}_{\mathrm{t}-1}+\sum_{\mathrm{i}=1}^{\mathrm{k}} \varphi_{\mathrm{i}} \Delta \mathrm{z}_{\mathrm{t}}$} \\
\hline \multirow[t]{2}{*}{ Breaks } & 1998:08 & 0.0819 & 0.041 & 0.0278 & 0.0001 & -0.2912 & & \\
\hline & 2006:10 & $(4.574)$ & (2.671) & (2.125) & (4.574) & $(-5.3341)$ & & \\
\hline
\end{tabular}
transition parameter.

The test statistics are in brackets. The critical values were as follows: $1 \%(-7.19), 5 \%(-6.75)$ and $10 \%(-6.48)$ for model $3,1 \% 6.37)$ for model $2,1 \%(-6.74), 5 \%(-6.16)$ and $10 \%(-5.89)$ for model 1 .

\begin{tabular}{|c|c|c|c|c|c|c|c|c|}
\hline \multirow{2}{*}{$\begin{array}{l}\text { Delay } \\
\text { parameter: } \\
\text { d }\end{array}$} & \multicolumn{2}{|c|}{ Linearity } & \multicolumn{2}{|c|}{$\mathrm{H}_{01}$} & \multicolumn{2}{|c|}{$\mathrm{H}_{02}$} & \multicolumn{2}{|c|}{$\mathrm{H}_{03}$} \\
\hline & F-stat & signif & F-stat & signif & F-stat & Signif & F-stat & Signif \\
\hline 1 & 21.462 & 0.000 & 48.73 & 0.000 & 6.287 & 0.0001 & 4.419 & 0.0017 \\
\hline 2 & 11.460 & 0.000 & 25.62 & 0.000 & 2.162 & 0.0728 & 5.029 & 0.0006 \\
\hline 3 & 10.474 & 0.000 & 22.84 & 0.000 & 4.930 & 0.0007 & 2.273 & 0.0610 \\
\hline 4 & 10.242 & 0.000 & 17.92 & 0.000 & 7.271 & 0.000 & 3.573 & 0.0071 \\
\hline
\end{tabular}

Table 5: Lumsdaine and Papell test results (1997)

Table 6: Results of the nonlinearity test. 


$$
\mathrm{Q}(\mathrm{p})=\frac{\sum \hat{\mathrm{e}}_{\mathrm{t}}^{2}-\sum \hat{\mathrm{a}}_{\mathrm{t}}^{2} /(\mathrm{p}+1)}{\sum \hat{\mathrm{a}}_{\mathrm{t}}^{2} / \mathrm{T}-\mathrm{k}-2 \mathrm{p}-1} \rightarrow \mathrm{F}(\mathrm{p}+1, \mathrm{~T}-\mathrm{k}-2 \mathrm{p}-1)
$$

with, $\hat{\mathrm{e}}_{\mathrm{t}}$ the estimated residue, coming from each recursive regression of the ordered observations, the estimated residue is associated with the regression of $\hat{\mathrm{e}}_{\mathrm{t}}$ on $\left(1, \mathrm{X}_{\mathrm{t}}^{\prime}\right)$. By applying the procedure test of Tsay [30] while supposing the possible definition of four values of delay parameter $\mathrm{d}=\{1,2,3,4\}$, the rule of selection is done by the choice of parameter $\mathrm{d}$ checking $\hat{F}(p, d)=\max _{d \in D} \hat{F}(p, d)$. This means that the parameter of delay $p=2$ with the result is the following; the delay parameter $d$ automatically doesn't exceed value 2 .

The result of the Fisher test (Table 7) leads to the choice of the delay parameter $d=1$ associated to the max value of the Fisher test $\ddot{F}(p, d)$ where the transition variable $\left(\mathrm{Z}_{\mathrm{t}-\mathrm{d}}=\mathrm{Z}_{\mathrm{t}-1}\right)$ represents the transition variable of the threshold representation within the framework of the cointegration theory between the Tunisian effective real exchange rate and fundamentals variables, such as, the terms of change (tot), the degree of openness (open), the value of net foreign assets (nfa), the Balassa Samuelson effect (balass), the differential of the real interest rate (dint), the differential and the public expenditure or the foreign debt (Dett) [31-34].

\begin{tabular}{|c|c|c|}
\hline \multirow{2}{*}{ Delay parameter } & \multicolumn{2}{|c|}{ Fisher Test } \\
\cline { 2 - 3 } & Valeur & Probabilite : P \\
\hline $\mathrm{d}=1$ & 48.84311 & $1.03921 \mathrm{e}-026$ \\
\hline $\mathrm{d}=2$ & 4.68806 & 0.00315 \\
\hline $\mathrm{d}=3$ & 12.87034 & $5.06472 \mathrm{e}-008$ \\
\hline $\mathrm{d}=4$ & 15.69875 & $1.22664 \mathrm{e}-009$ \\
\hline
\end{tabular}

Table 7: Results of the fisher test.

\section{Threshold ECM estimation results}

The error correction mechanism $(Z\{1\})$ is significant only in the first component where it schematizes a divergence for the process adjustment towards the long run relationship [35]. On the one hand, it can be noted that the coefficient identifying the error correction mechanism is negative and significant only for regime $1(-0.157$ $(0.0039))$. On the other hand, this short- term mechanism is negative but not significant in regime $2(-0.025(0,1677))$. So, the nonlinearity in the cointegration relationship is confirmed through the discontinuity in the short-term adjustment. Thus, the convergence process towards the long-term target will be activated according to the transition variable position compared to the threshold parameters. For regime 1, which corresponds to the case where the transition variable is greater than the threshold $\mathrm{c}$ 1, the convergence process towards the long-term target is carried out through the short-term adjustments or short-run dynamics of exchange rate. A threshold ECM model with two states is, therefore, sufficient to explain the discontinuity in the convergence process of the effective exchange rate of the Tunisian dinar. So, these two states of the system that explain this discontinuity must be identified which is shown in the Table 8.

The trajectory of the misalignment can confirm that the convergence process of the effective exchange rate of the Tunisian dinar towards its fundamental situation is characterized by nonlinearities, depending on whether Tunisia exchange rate is in under or overvaluation regimes [36-38]. In order to specify the trajectory of the misalignment of the effective exchange rate, the extent or degree of misalignment during the period 1980 to 2012 is graphically illustrated. The following graphic representation demonstrates the divergence between the different trajectories as in the Figure 9.

\begin{tabular}{|c|c|c|c|c|c|c|}
\hline \multirow[t]{2}{*}{ Variables } & \multicolumn{2}{|c|}{ Regime 1} & \multicolumn{2}{|c|}{ Regime 2} & \multicolumn{2}{|c|}{ Regime 3} \\
\hline & Coeff & Signif & Coeff & Signif & Coeff & Signif \\
\hline Constant & 0.0433 & 0.0082 & 0.0122 & 0.307 & -0.0031 & 0.659 \\
\hline$Z\{1\}$ & -0.157 & 0.0039 & -0.025 & 0.167 & 0.0001 & 0.990 \\
\hline $\operatorname{DRER}\{1\}$ & 0.1963 & 0.0089 & 0.0873 & 0.495 & 0.104 & 0.196 \\
\hline $\operatorname{DGOP}\{1\}$ & 1.170 & 0.047 & -0.39 & 0.283 & -0.315 & 0.103 \\
\hline DTOT $\{1\}$ & -1.1759 & 0.602 & -0.767 & 0.588 & 0.327 & 0.483 \\
\hline DGOV $\{1\}$ & -4.581 & 0.445 & 0.235 & 0.906 & 0.66 & 0.533 \\
\hline DNFA $\{1\}$ & -57.35 & 0.023 & 13.46 & 0.79 & -28.33 & 0.031 \\
\hline DBALAS $\{1\}$ & 16.38 & 0.0009 & 0.918 & 0.618 & 0.455 & 0.818 \\
\hline DDPI $\{1\}$ & 0.0047 & 0.768 & -0.004 & 0.44 & -0.0028 & 0.537 \\
\hline $\mathrm{DDI}\{1\}$ & -4.396 & 0.038 & 11.67 & 0.412 & 1.007 & 0.6083 \\
\hline
\end{tabular}

Table 8: Estimation results of threshold error correction model.

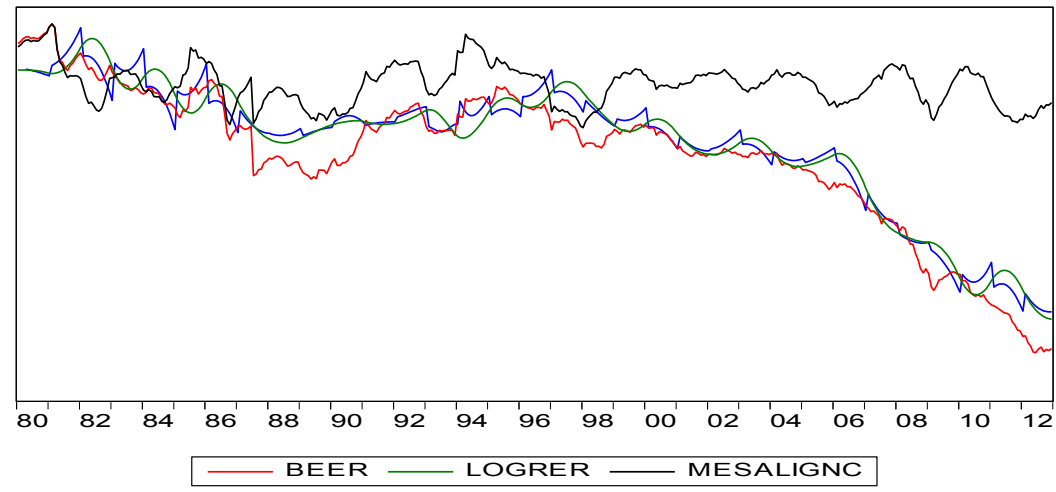

Figure 9: Graphics of misalignment trajectory. 
It can be deduced that Tunisia has undergone a significant under evaluation of the dinar versus the currencies of the trade partners during the study period from 1980 to 2012 when the real effective exchange rate observed (rer) is higher than the real equilibrium real exchange rate (BEER). The specificity of the misalignment of the effective exchange rate of the Tunisian dinar justifies the threshold modeling of convergence processes followed in this study through the nonlinear cointegration theory: the misalignment process adjustment takes place in specific period and the speed of adjustment varies with the extent of the deviation from equilibrium. Moreover, by applying the threshold cointegration theory, we find that this process seems to run only for a single component or regime [39-41]. By identifying the two regimes mentioned above, it follows that the convergence process takes place exclusively in undervaluation situation. Whenever there is undervaluation, the observed exchange rate converges towards the equilibrium situation and vice versa. The result obtained confirms the discontinuous or asymmetrical character of the trajectory of the Tunisian dinar towards its fundamental situation [42-44].

\section{Conclusion}

The study of the misalignment of the Tunisian dinar exchange rate is indispensable since this long-term variability towards equilibrium target reflects a bad exchange rate policy. A positive misalignment reflects an undervaluation of the exchange rate while a negative misalignment reflects an overvaluation of the exchange rate. Indeed, it has been proven that the convergence process of the effective exchange rate of the Tunisian dinar towards its fundamental situation is characterized by nonlinearities, depending on whether Tunisia is in under- or overvaluation regimes.

In addition, structural shifts from selected economic variables, such as the terms of trade (tot), the open rate (open), the net value of foreign assets (nfa), the Balassa Samuelson effect (balass), The real interest rate differential (dint) and public expenditure (gov) may characterize this discontinuity in the convergence process. Structural breaks can lead to exchange rate expectations that are not compatible with the trajectory of the fundamentals.

\section{References}

1. Christian $U$ (2009) Forecasting and Hedging in the Foreign Exchange Markets. Lecture Notes in Economics and Mathematical Systems.

2. Frankel JA, Rose AK (1995) Empirical research on nominal exchange rates. In: Grossman, Gene, Rogoff, Kenneth editors. Handbook of International Economics 3: 1689-1729.

3. Macdonald R, Frommel M, Menkhoff $L$ (2005) Markov switching regimes in a monetary exchange rate model. Economic Modelling 22: 485-502.

4. Balke NS, Fomby TB (1997) Threshold Cointegration. International Economic Review 38: 627-645.

5. Taylor MP, Peel DA, Sarno L (2001) Nonlinear mean-reversion in real exchange rates: To wards a solution to the Purchasing Power Parity Puzzles. International economic review 42: 1015-1042.

6. Bessec M (2002) Mean-reversion versus adjustment to PPP: The two regimes of exchange rate dynamics under the EMS, 1979-1998. Economic Modelling 20: $141-164$.

7. Martens M, kofman P, Vorst TCF (1998) A threshold error correction model for intraday futures and index returns. Journal of applied econometrics 13: 245263.

8. Michael P, Nobay AR, Peel DA (1997) Transactions costs and nonlinear adjustment in real exchange rates: An empirical investigation. The Journal of Political Economy 105: 862-879.

9. Tsay RS (1989) Testing and Modeling Threshold Autoregressive Processes. Journal of the American Statistical Association 84: 231-240.
10. Taylor MP, Peel DA (2000) Nonlinear adjustment, long-run equilibrium and exchange rate fundamentals. Journal of International Money and Finance 19: 33-53.

11. Sercu P, Uppal R, Van Hulle C (1995) The exchange rate in the presence of transaction costs: implications for tests of Purchasing Power Parity. Journal of finance 50: 1309-1319.

12. Enders W, Siklos PL (2001) Cointegration and threshold adjustment. Journal of Business and Economic statistics 19: 166-176.

13. Caner M, Hansen BE (2001) Threshold Autoregression with unit root. Econometrica 69: 1555-1596.

14. Colletaz G, Hurlin C (2006) Threshold effects in the public capital productivity: an international panel smooth transition approach. Document de Recherche, Laboratoire d'Economie d'Orléans.

15. Hamilton JD (1990) Analysis of Time Series Subject to Changes in Regime. Journal of Econometrics 45: 39-70.

16. Boutahar M, Mootamri I, Feissolle AP (2009) A Fractionally Integrated Exponential STAR model applied to the US real effective exchange rate. Economic Modelling 26: 335-341.

17. Engel C, Hamilton JD (1990) Long swings in the dollar. Are they in the data and Do markets know it? American Economic Review 80: 689-713.

18. Marimoutou V, Bouoiyour J, Roy S (2004) Real equilibrium exchange rate and exchange rate policy in Morocco: a non-parametric approach. Economic International 97: 81-104.

19. Fok D, Van Dijk D, Franses PH (2003) A multi-level Panel Smooth Transition auto regression for US sectoral production. Econometric Institute Report No 43

20. Teräsvirta T (1994) Specification, Estimation, and Evaluation of smooth transition autoregressive models. Journal of the American Statistical Association 89: 208-218.

21. Hansen BE (1996) Inference when a nuisance parameter is not identified under the null hypothesis. Econometrica $64:$ 413-430.

22. Hansen BE, Seo B (2002) Testing for two regime threshold cointegration in vector error correction models. Journal of econometrics 110: 293-318.

23. Gregory AW, Hansen BE (1996) Residual based tests for cointegration in models with regime shifts. Journal of Econometrics 70: 99-126.

24. Aslanidis N, Kouretas GP (2005) Testing for two regime threshold cointegration in the parallel and official markets for foreign currency in Greece. Economic Modelling 22: 665-682.

25. Hansen BE (1999) Threshold effects in non-dynamic panels: Estimation, Testing, and Inference. Journal of Econometrics 93: 345-368

26. Levin A, Lin C, Chu C (2002) Unit root test in panel data: asymptotic and finite sample properties. Journal of Econometrics 108: 1-24.

27. Teräsvirta T, Anderson HM (1992) Characterizing nonlinearities in business cycles using smooth transition autoregressive models. Journal of Applied. Econometrics 7: 119-136.

28. Hansen BE (1997) Inference in TAR models. Studies in Nonlinear Dynamics and Econometrics 2: 1-14.

29. Hall S, Psaradakis Z, Sola M (1997) Switching error correction models of house prices in the united kingdom. Economic Modelling 14: 517-527.

30. Tsay RS (1998) Testing and modelling multivariate threshold models. Journa of the American Statistical Association 93: 1188-1202.

31. Sabourin P, Lalonde R (2003) Modeling and forecasting of the US real effective exchange rate.

32. Van Dijk D, Teräsvirta T, Franses PH (2000) Smooth transition autoregression models: A survey of recent developments. Econometrics Review 21: 1-47.

33. Bellone B (2005) Classical estimation of multivariate markov switching model with MSVARLIB. Econ WPA, Econometrics, pp: 1-27.

34. Béreau S, Villavicencio AL, Mignon V (2000) Nonlinear adjustment of the real exchange rate towards its equilibrium value: A panel smooth transition errcorrection modelling. Economic modelling 27: 404-416.

35. Brenner RJ, Kroner KF (1995) Arbitrage, Cointegration, and Testing the Unbiasedness Hypothesis in Financial Markets. Journal of Financial and Quantitative Analysis 30: 23-42. 
Citation: Sami R, Saoussen K (2017) A Study of the Regime Switching in the Relationship between the Tunisian Exchange Rates and the Fundamental Economic Variables: A Further Investigation Using the Threshold Cointegration Theory. J Glob Econ 5: 266. doi: 10.4172/2375-4389.1000266

36. Chen CWS, Lee JC (1995) Bayesian Inference of Threshold Autoregressive Models. Journal of Time Series Analysis 16: 483-492.

37. Eitrheim $\varnothing$, Teräsvirta $T$ (1996) Testing the adequacy of smooth transition autoregressive models. J. Econometrics 74: 59-75.

38. Goldfeld SM, Quandt RE (1973) A Markov model for switching regressions. Journal of Econometrics 1: 3-15.

39. González A, Teräsvirta T, van Dijk D (2005) Panel Smooth Transition Regression model. SSE/EFI Working Paper Series in Economics and Finance 604, Stockholm School of Economics.
40. Gray SF, Dahlquist M (2000) Regime-switching and interest rates in the European monetarysystem. Journal of international Economics 50: 399-419.

41. Hadri K, Pearson M, Yongcheol S (2000) Testing for unit roots in heterogeneous panel data. Journal of Econometrics 115: 53-74.

42. Hairault JO, Sopraseuth $\mathrm{T}$ (2008) International Fluctuation and Exchange Rate Dynamics. Economie et prévision 183: 65-91.

43. Hamilton JD (1996) Specification testing in Markov-switching time-series models. Journal of Econometrics 70: 127-157.

44. Im K, Pesaran M, Shin Y (2003) Testing for unit roots in heterogeneous panels. Journal of Econometrics 115: 53-74. 